\title{
Thoracoplasty in the Management of Chronic Empyema: Experience of a Sub Saharan African Country
}

\author{
Assane Ndiaye, Souleymane Diatta, David Douglas Banga Nkomo, Papa Salmane Ba, \\ Modibo Doumbia, Adama Sawadogo", Magaye Gaye, Fokalbo Zephanie Kobe, \\ Momar Sokhna Diop, Ndeye Fatou Sow, Gabriel Amadou Ciss, Pape Adama Dieng, \\ Mohamadou Lamine Fall, Mouhamadou Ndiaye
}

Department of Thoracic and Cardiovascular Surgery, University Hospital of Fann, Dakar, Senegal

Email address:

adamsaw2000@yahoo.fr (A. Sawadogo)

${ }^{*}$ Corresponding author

\section{To cite this article:}

Assane Ndiaye, Souleymane Diatta, David Douglas Banga Nkomo, Papa Salmane Ba, Modibo Doumbia, Adama Sawadogo, Magaye Gaye, Fokalbo Zephanie Kobe, Momar Sokhna Diop, Ndeye Fatou Sow, Gabriel Amadou Ciss, Pape Adama Dieng, Mohamadou Lamine Fall, Mouhamadou Ndiaye. Thoracoplasty in the Management of Chronic Empyema: Experience of a Sub Saharan African Country. International Journal of Cardiovascular and Thoracic Surgery. Vol. 3, No. 6, 2017, pp. 70-74. doi: 10.11648/j.ijcts.20170306.12

Received: August 3, 2017; Accepted: August 11, 2017; Published: December 6, 2017

\begin{abstract}
Introduction: The current main indication of thoracoplasty is empyema following or not lung resection, when the other surgical methods such as thoracic drainage, pleurostomy and/or pulmonary decortication have failed or are not useful. The authors report the role of thoracoplasty in the management of chronic empyema. Method: Between 2004 and 2015, eight male patients underwent thoracoplasty, in the Department of Thoracic Surgery at the University Hospital of Fann, Dakar, Senegal. The mean age was 40 years old. In all cases, the first step of the treatment was thoracic drainage with Heimlich valve in an ambulatory patient, associated with antibiotic according to the result of bacterial culture. In three patients, thoracostomy was indicated to control local infection before thoracoplasty. Results: Indications for thoracoplasty were refractory post resectionnal lung empyema in 6 cases and chronic primary apical empyema in 2 cases. Bronchopleural fistula was found in 5 patients. We performed three superior partial thoracoplasty, and five enlarged thoracoplasty. A myoplasty, using latissimus dorsi to fill the empyema space, was associated with thoracoplasty in five cases. Bronchopleural fistula cure consisted of a direct $\mathrm{X}$ form suture in two cases and of intercostal muscle apposition on the fistula in others ones. Partial scapulectomy, by resection of the inferior third part of the scapula was done in three patients. After a mean follow up of one year, no patient presented with persistence or recurrence of empyema. Then we concluded that they were healed. Conclusion: Thoracoplasty is an efficient procedure for the management of chronic empyema. So it is necessary for each team to established define criteria that will allow a patient to undergo thoracoplasty in order to do not use it for any desperate case of refractory chronic empyema.
\end{abstract}

Keywords: Thoracoplasty, Bronchopleural Fistula, Empyema, Tuberculosis

\section{Introduction}

The current main indication of thoracoplasty is empyema following lung resection [1]; [2]. The goal of this surgical procedure is to obliterate the empyema space by remodeling the thoracic wall and it consists of many variants [3]. It is generally indicated when the other surgical methods such as thoracic drainage, open window thoracostomy (OWT) and/or pulmonary decortication have failed or are not useful.

The aims of this study are to report the outcome of the patients who underwent this procedure and determine its place in the management of chronic empyema in our practice

\section{Patients and Methods}

A retrospective study was conducted from 2004 to 2015. Over this period, eight male patients underwent thoracoplasty. Their ages ranged from 18 to 65 years old (yo) with a mean age of 40 yo. One of them was diabetic. Six patients previously had lung resection: left pneumonectomy in four of 
them and right upper lobectomy in the last two. One of the upper lobectomy was done during a pulmonary decortication.

The two patients without history of previous lung resection had lung function impairment with forced expiratory volume in one second under 1.5 liter/second, due to bilateral parenchymal lung sequelae of tuberculosis. That did not allow them to undergo decortication associated to lung resection.

The time taken for the onset of the empyema after lung resection varied from 3 months to 20 years. The symptoms consisted of chest pain, dyspnea, cough, purulent sputum and fever.
All patients were thin with a body mass index (BMI) ranging from 16 to 17.17 and their HIV serology was negative. Primary affection was pulmonary TB in all cases. Acid-Fast Bacilli from sputum was negative for all patients. Preoperative analysis of the swab pus permitted the isolation of the germs only among five patients who had a lung resection. The germs isolated were Pseudomonas aeruginosa, Staphylococcus aureus; Enterobacter spp, Klebsiella pneumoniae, Streptococcus spp, Escherichia coli and flavobacterium spp. Bronchopleural fistula was found in five patients (figure 1).

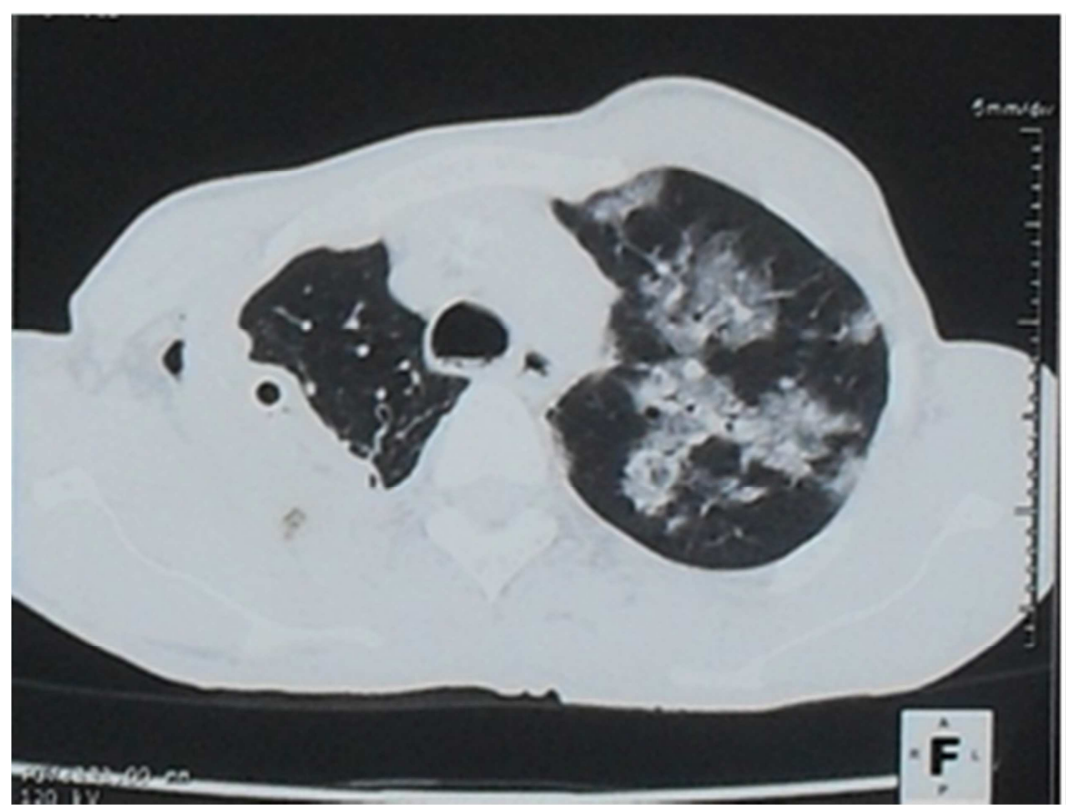

Figure 1. Chest CT showing refractory chronic primary apical empyema

In all cases, the first step of the treatment was thoracic drainage with Heimlich valve in an ambulatory patient, associated with antibiotic regimen guided by bacterial culture result. After this drainage, if the infection was controlled, the patient underwent thoracoplasty. On the contrary, OWT was firstly performed followed by thoracoplasty.

Thoracoplasty was performed in one stage. A general anesthesia with a double lumen endotracheal tube was used in all cases. Epidural catheter was inserted in all patients to prevent post-operative pain.

The approach for the thoracoplasty was posterolateral thoracotomy. The incision follows the scar of the previous thoracotomy, with the edges of the OWT for those patients who previously had it. This approach was realized without resection of latissimus dorsi and serratus muscle. Following identification and marking of the lower area of resection, the rib cage was freed, anteriorly by section of the digitations of the major serratus inserted on the second and third ribs, and posteriorly by disinsertion of the minor serratus on the para vertebral muscles. Following this step, we did ribs resection by leaving the periosteal bed in place. The excision of the first and the second ribs were always complete whereas the removal of the others ribs was partial.

To fill the empyema cavity, we used latissimus dorsi.
Bronchopleural fistula (BPF) repair consist of a direct $\mathrm{X}$ form suture or of intercostal muscle apposition. Partial scapulectomy, by resection of the inferior third part was done when we resect more than five ribs. All patients had postoperative drainage and subcutaneous drainage.

Finally, to enhance cavity obliteration, and to reduce the risk of occurrence of paradoxical respiration, a pad was placed in the axilla of the operated side, and it was maintained by a torso bandage.

Patients were reevaluated at one month, three months, six months, one year and then every one year after the surgery. The criteria for thoracoplasty success were resolution of empyema, obliteration of the cavity, and the closure of the BPF when present. The figure 2 shows one of the patients five years after thoracoplasty.

\section{Results}

Indication for thoracoplasty was refractory post pneumonectomy empyema (RPPE) in 4 cases, refractory post upper lobectomy empyema (RPULE) in 2 cases and refractory chronic primary apical empyema (RCPAE) in 2 cases.

BPF was associated to RPPE, RPULE and to RCPAE in 
two cases for each.

In four patients, OWT was needed and the duration of this one ranged from 3 to 18 months.

Three superior partial thoracoplasty have been performed. It consisted of resection of the first four ribs in the two patients with RCPAE and in one with RPULE. The others patients had an enlarged thoracoplasty by resection of five or six ribs, without resection of the first rib. Thoracoplasty was associated to a myoplasty in five patients.
A direct $\mathrm{X}$ form suture, and intercostal muscle apposition were used to repair BPF, respectively in two and four patients. Partial scapulectomy was done in five patients.

The post-operative drainage lasted from 7 to 36 days with a mean duration of 17 days. The duration of omo-serratic drainage, done in three patients and the duration of subpectoral drainage done in one patient were 4 days.

The preoperative status and surgical procedure are summarized in table 1.

Table 1. Preoperative status and surgical procedures of the patients.

\begin{tabular}{|c|c|c|c|c|c|}
\hline & Age & Type of previous lung resevtion & OWT & BPF & Indication for thoracoplasty \\
\hline Patient $n^{\circ} 1$ & 21 & None & Yes & Yes & RCPAE associated with persistent BPF \\
\hline Patient $n^{\circ} 2$ & 65 & Right upper lobectomy & No & Yes & RPULE associated with persistent BPF \\
\hline Patient $n^{\circ} 3$ & 26 & Left pneumonectomy & No & No & RPPE \\
\hline Patient $n^{\circ} 5$ & 51 & None & Yes & Yes & RCPAE associated with persistent BPF \\
\hline Patient $n^{\circ} 6$ & 40 & Left pneumonectomy & Yes & No & RPPE associated with persistent BPF \\
\hline Patient $n^{\circ} 7$ & 47 & Left pneumonectomy & Yes & Yes & RPPE \\
\hline
\end{tabular}

Table 1. Continued.

\begin{tabular}{|c|c|c|c|c|}
\hline & Extent of rib resection for thoracoplasty & Myoplasty & Scapulectomy & Techniques of BPF repair \\
\hline Patient $n^{\circ} 1$ & $\mathrm{C} 1-\mathrm{C} 2-\mathrm{C} 3-\mathrm{C} 4$ & Yes & No & Intercostal muscle apposition \\
\hline Patient $n^{\circ} 2$ & $\mathrm{C} 2-\mathrm{C} 3-\mathrm{C} 4-\mathrm{C} 5-\mathrm{C} 6$ & Yes & Yes & $\mathrm{X}$ form suture \\
\hline Patient $n^{\circ} 3$ & $\mathrm{C} 2-\mathrm{C} 3-\mathrm{C} 4-\mathrm{C} 5-\mathrm{C} 6$ & Yes & Yes & \\
\hline Patient $n^{\circ} 5$ & $\mathrm{C} 1-\mathrm{C} 2-\mathrm{C} 3-\mathrm{C} 4$ & No & No & $\mathrm{X}$ form suture \\
\hline Patient $n^{\circ} 6$ & $\mathrm{C} 2-\mathrm{C} 3-\mathrm{C} 4-\mathrm{C} 5-\mathrm{C} 6$ & Yes & Yes & \\
\hline Patient $n^{\circ} 7$ & $\mathrm{C} 2-\mathrm{C} 3-\mathrm{C} 4-\mathrm{C} 5-\mathrm{C} 6-\mathrm{C} 7$ & No & Yes & Intercostal muscle apposition \\
\hline
\end{tabular}

Legendes: RCPAE: refractory chronic primary apical empyema

RPPE: refractory post pneumonectomy empyema

RPULE: refractory post upper lobectomy empyema

Wound suppuration, noticed in 4 patients, was the main post-operative complication, and contributed to the late healing in our patients, lasting between 1 to 5 months.

No decease was noticed during the early post-operative period. After a mean follow up of one year, no patient presented with persistence or recurrence of empyema. Thus the conclusion was that empyema were resolved (figures 2 and 3).

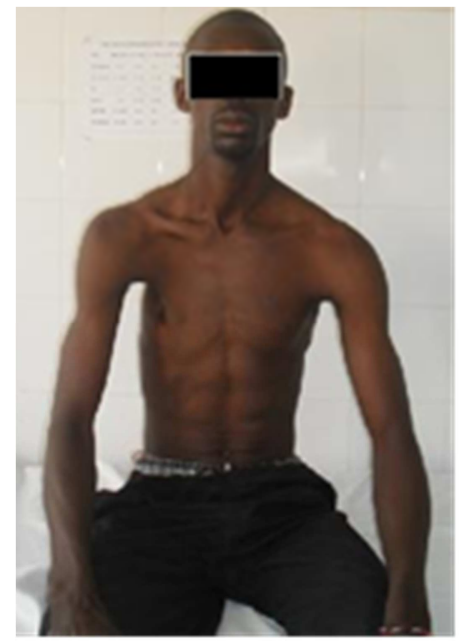

Figure 2. A patient after thoracoplasty (undressed).
Two patients with RPPE died, respectively one and two years after thoracoplasty. The death was due to severe hemoptysis in one patient and in the other one, it was due to right heart failure secondary to pulmonary hypertension. The others one was free of initial symptom so they were fully reinserted in their social environment and going back to work.

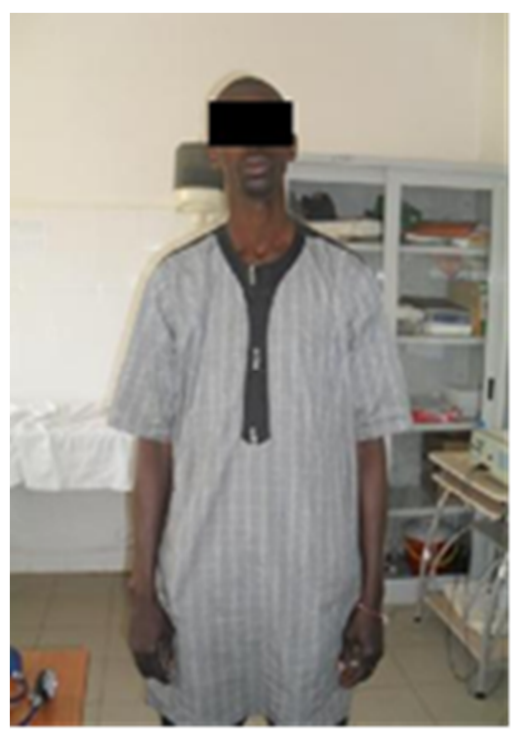

Figure 3. The same patient (dressed). 


\section{Discussion}

Nowadays, thoracoplasty is less used in thoracic surgery. In published reports, with the exception of Dewann's series [4], authors generally mention a few cases given to the study's duration [2], [5], [6]. In developing and underdeveloped countries like Senegal, the patients are younger, and primary pathology is infection [4]. On the contrary, studies in developed countries showed a mean age generally up to 60 years, with malignancies as leading affection while infectious pathologies were seen on the decline [2], [5], [7], [8].

Although pulmonary indications are declining due to the well spread antituberculosis drugs [3], some cases have been reported in recent studies [1], [5], [4]. Indications of thoracoplasty are still dominated by post resectionnal lung empyema, especially PPE [9]. Prevention of complication related to persistent residual pleural space after lung resection, especially after upper lobectomy is also another uncommon indication of thoracoplasty [10].

The surgical methods for the treatment of chronic empyema following or not lung resection are known and consist of thoracic drainage, thoracic drainage with irrigation of the pleural cavity, video-assisted thoracoscopic surgery debridement, OWT, pulmonary decortications when the adjacent lung have the capacity to reexpand, thoracoplasty and recently vacuum-assisted closure [11], [12], [13], [14], [15].

Thoracoplasty is a surgical procedure generally applicable to patients with a chronic refractory empyema that cannot undergo lung resection because of a previous pneumonectomy or because of inability to support major lung resection due to the impairment of lung function, and lastly for those that cannot undergo lung decortication due to inability of underlying lung to expand [3], [5], [7], [8], [16].

As there is no definition of chronic refractory empyema based on duration, in our department, the fixed term for healing time in primary chronic empyema and in post pneumonectomy empyema was 3 months after a well conducted antibiotic cure according to guidelines or result of susceptibility studies of causative organism.

Since then we decided to perform thoracoplasty in patients who present with unresolving empyema. This term was reduced to 1 month in patient with PULE.

That management always begin with a control of local infection by means of thoracic drainage or OWT, and ended by obliteration of empyema cavity using thoracoplasty or thoracomyoplasty. Indeed, that control increases the chances of success of that surgical procedure [2], [6], [17].

The success rate of thoracoplasty was generally greater than $85 \%$ and post-operative mortality rate was low [5], [6], [16], [18], [19]. These reasons argue for the choice of thoracoplasty as a therapeutic procedure of refractory chronic empyema.

Thoracoplasty and myoplasty were generally combined when it is thought that the cavity is large-sized and cannot be obliterated by thoracoplasty alone, or it cannot be filled by a flap's transposition alone and finally, when bronchopleural fistula is associated to empyema [5].

The morbidity usually high, as seen in our series and the disadvantageous cosmetical appearance of this procedure argue against its use [3], [5], [9], [16]. But as the patients are well rehabilitated, the acceptation of their new physical appearance is easier.

\section{Conclusion}

Although thoracoplasty is 'mutilating' and aggressive with impact to cosmetical appearance, it remains an efficient procedure for the management of chronic empyema. It must be included in a clearly established therapeutic strategy. So it is necessary for each team to establish criteria that will allow a patient to undergo thoracoplasty.

\section{References}

[1] Botianu AM, Botianu PV. Modified thoraco-mediastinal plication (Andrews thoracoplasty) for post- pneumonectomy empyema: experience with 30 consecutive cases. Interact Cardiovasc Thorac Surg. 2013; 16: 173-8.

[2] Hopkins RA, Ungerleider RM, Staub EW, Young WG. The modern use of thoracoplasty. Ann. Thorac. Surg. 1985; 40:181-187.

[3] Botianu AM, Botianu PV. Role of thoracomyoplasty procedures in modern surgery for intrathoracic suppurations. In: Cardosso P. F. G. Topics in Thoracic Surgery. In Tech Ed., Rijeka, Croatia; 2012. p. 309-26.

[4] R. K. Dewan, Sanjay Singh, Ashwini Kumar1, and Bhupender K. Meena. Thoracoplasty: An Obsolete Procedure? Indian J Chest Dis Allied Set 1999; 41: 83-8.

[5] Krassas A, Grima R, Bagan P, Badia A, Arame A, Le Pimpec Barthes $F$, Riquet $M$. Current indications and results for thoracoplasty and intrathoracic muscle transposition. Eur J Cardiothorac Surg 2010; 37: 1215-20.

[6] Peppas G, Molnar TF, Jeyasingham K, Kirk AB. Thoracoplasty in the context of current surgical practice. Ann Thorac Surg 1993; 56:903-9.

[7] Stefani A, Jouni R, Alifano M, Bobbio A, Strano S, Magdeleinat $\mathrm{P}$ and Regnard JF. Thoracoplasty in the Current Practice of Thoracic Surgery: A Single-Institution 10-Year Experience. Ann Thorac Surg 2011; 91:263-8.

[8] Icard P, Le Rochais JP, Rabut B, Cazaban S, Martel B, Evrard C. Andrews thoracoplasty as a treatment of postpneumonectomy empyema: experience in 23 cases. Ann Thorac Surg 1999; 68: 1159-64.

[9] Melki J, Lachkar S, Peillon C, Testart J, Muir JF, Thiberville L. Thoracoplastie Osteoplastique de BJÖRK. Indications et résultats. A propos d'une série de 29 patients. Chirurgie Thoracique Cardio-Vasculaire - 2008; 12: 88-94.

[10] Pairolero P. C., Trastek MD, Trastek Victor F. Surgical Management of Chronic Empyema: The Role of Thoracoplasty. Ann Thorac Surg 1990; 50: 689-90. 
[11] Scarci M, Abah U, Solli P, Page A, Waller D, van Schil P et al EACTS expert consensus statement for surgical management of pleural empyema. Eur J Cardiothorac Surg 2015; 48: 64253.

[12] Zahid I, Routledge T, Billè A, Scarci M. What is the best treatment of postpneumonectomy empyema? Interact CardioVasc Thorac Surg 2011; 12: 260-4.

[13] Jadczuk E. Postpneumonectomy empyema. Eur J Cardiothorac Surg, 1998; 8: 123-6.

[14] Miller JI, Mansour KA, Nahaï F, Jurkiewicz MJ, Hatcher CR. Single stage complete muscle flap closure of post pneumonectomy empyema space: a new method and possible solution to a disturbing complication. Ann Thorac Surg 1984; 38: $227-31$.
[15] Pairolero PC; Arnold PG; Trastek VF, Meland BN, Kay PP. Post pneumonectomy empyema: role of intratoracic muscle transposition. J. Thorac Cardiovasc. Surg. 1990; 99: 958-68

[16] Botianu PV, Botianu AM. Thoracomyoplasty in the treatment of empyema: current indications, basic principles, and results. Pulm Med 2012; 2012: 418514.

[17] Garcia-Yuste M, Ramos G, Duque JL. Open-window thoracostomy and thoracomyoplasty to manage chronic pleural empyema. Ann Thorac Surg 1998; 65: 818-22.

[18] Jaretzki A III. Role of thoracoplasty in the treatment of chronic empyema [Letter]. Ann Thorac Surg 1991; 52: 584-5.

[19] Wong PS, Goldstraw P. Post-pneumonectomy empyema. Eur J Cardiothorac Surg 1994; 7:345-50. 